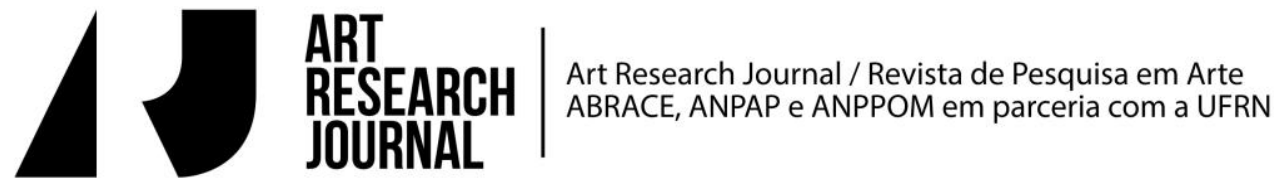

\section{Barcarola op. 60 de F. Chopin: Etapas e estratégias de aprendizagem}

\author{
Cristina Capparelli Gerling \\ PPGMUS/UFRGS
}

No início do novo século Clarke (2004) afirmou que a performance musical se configura como a realização humana da mais alta complexidade resultante de um investimento maciço de tempo e esforço. Huron (2007), por sua vez vem nos aconselhando a abandonar os aspectos primários de sensações e percepções para investirmos na dimensão da criatividade e da imaginação em contextos musicais reais. Assim, escolhi uma obra de grande porte e comprovado nível de desafios musicais e pianísticos como ponto de partida. Este trabalho é um relato parcial de algumas das etapas percorridas na aprendizagem, memorização e apresentação da Barcarola op. 60 de Chopin.

Se o índice de sucesso de um compositor pode ser medido em número de estreias e encomendas de novas obras, um instrumentista por seu turno pode tornar-se conhecido por suas interpretações de determinado grupo de obras ou mesmo de determinados compositores, ambos revisitados ao longo da vida. Isto se deve ao paradoxo de que cabe ao executante ler a partitura com absoluta fidedignidade e, também, ultrapassar o que está explicitamente anotado para atingir um patamar interpretativo singular. Além disso, este instrumentista ganha ao estabelecer um forte elo de comunicação com sua audiência através de suas intenções expressivas clara e intensamente projetadas. Como vencer este desafio? Com ambição, talento e sorte seria a explicação do senso comum. Como pianista e pesquisadora, no entanto, comprovo que o "investimento maciço de tempo e esforço" mencionado anteriormente ganha na parceria com a psicologia da música e no fomento aos estudos guiados pela prática. A prática deliberada ou efetiva baseada em planejamentos e resultados tem no intérprete o principal 
parceiro e colaborador no campo da musicologia cognitiva. Em termos de prática instrumental, a prática deliberada discutida na literatura por diversos autores (Ericsson et al., 1997; Weisberg, 1999), vem apontando diferentes perspectivas sendo que o ponto em comum é o desempenho do profissional, do perito ou especialista como fonte singular desse tipo de procedimento. Com isto forma-se um círculo virtuoso de previsão, sucesso e análise de resultados.

A literatura recente aponta para um incremento exponencial no numero e na qualidade de trabalhos sobre a interpretação e a execução, trabalhos guiados e impulsionados pela prática. ${ }^{1}$ Partindo desta premissa, a partir de 2008 estou envolvida em uma pesquisa longitudinal do meu próprio estudo de uma obra de inegável porte e importância no repertório pianístico. Trata-se de um estudo da Barcarola op. 60 escrita por Frederic Chopin (1810-1849) em 1845 e publicada em 1846 organizado nas seguintes etapas: 1) comparação de edições; 2) análise para performance; 3) comparação de análises; 4) registro e análise das primeiras seções de estudo; 5) prática deliberada e estratégias de memorização 6) análise de performances e comparação de gravações.

\section{Comparação de edições}

Seguindo a prática do seu tempo e, buscando entre outros expedientes, auferir maior ganho da sua produção, Chopin enviou manuscritos com diferenças significativas na escrita musical para casas editoras na França, Alemanha e Inglaterra, seus principais mercados. Ao driblar as leis do direito autoral no século XIX, ele produziu variedade suficiente nos textos para deixar os editores modernos perplexos com a quantidade de variações entre as fontes. Além dos manuscritos, existem "três" primeiras edições diferenciadas entre si para a maioria das suas composições disponibilizadas atualmente em (Fig. 1):

1 http://www.creativityandcognition.com/research/practice-based-research/differences-betweenpractice-based-and-practice-led-research/. Acesso em 23 abr. 2013. 


\begin{tabular}{|c|c|}
\hline \multicolumn{2}{|c|}{ Fontes de Consulta para Edições online de Chopin } \\
\hline http://www.chopin.pl/edycja 1999 2009/recepcja/edytorstwo muzyczne/wydaw \\
\hline \multicolumn{2}{|c|}{ nut en.html\#11 } \\
\hline http://www.cfeo.org.uk/apps/ & $\underline{\text { http://chopin.lib.uchicago.edu/ }}$ \\
\hline
\end{tabular}

Figura 1. Fontes de Consulta para Edições de Chopin online.

Além de variantes na escrita de obras, Chopin incorreu em alguns erros de cópia no mínimo problemáticos, como é o caso do retorno do tema $A^{\prime}$ nos compassos 84-92, ou ainda nas tentativas de correção do exemplo seguinte (Rink, 1988, p. 208-209), como explicitado a seguir (Fig. 2 e 3):

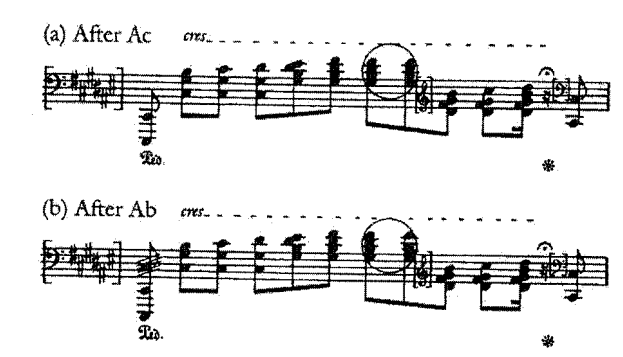

Figura 2. Divergência na mão esquerda no c. 92.

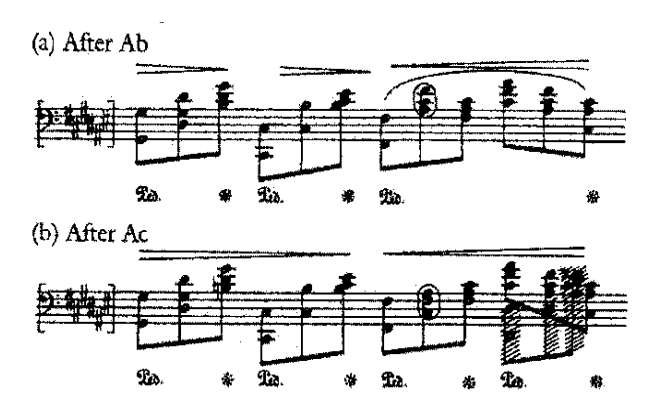

Figura 3. Rasuras na mão esquerda, c. 97.

Inconstâncias ou erros encontrados na partitura assombram as edições disponíveis tanto nas impressas quanto nas acessíveis por meio eletrônico. 0 resultado prático desta constatação é que cada pianista ao consultar as fontes disponíveis constrói sua própria edição de trabalho, evidenciando assim uma série de escolhas possíveis dadas às alternativas textuais. Cada pianista poderá ter uma versão autêntica, resultante de pesquisa textual ou, seguindo o próprio compositor, poderá oferecer alternativas de leitura que considerem questões de pedais do piano, da ressonância da sala ou do estado de sua imaginação em um 
dado momento. Durante o período mais crítico do aprendizado utilizei como ponto de partida a edição oferecida pelo Instituto Chopin da Polônia (1984, Institut Fryderyka Chopina, Warsaw, Poland, ISBN 83-224-2212-1).

\section{Análise para performance e comparação de análises}

O doce balanço de barcos na água redondeia as barcarolas em contraste com os acentos marcados das patas de cavalos e a quadratura dos allegros. A Barcarola de Chopin, parente próxima das berceuses e noturnos, constitui-se em um dos gêneros mais característicos no século $X I X .^{2}$ A figuração em tercinas já fora evocada por Beethoven (op. 81a, terceiro movimento), no Otello de Rossini e em tantos outros números da música vocal e instrumental. Barcarolas podem sinalizar a passagem entre esta vida e outra, seja no sonho passageiro ou no eterno. Frequentemente evoca um afastamento fluído ainda que inexorável, uma transposição para o incessível e o sobrenatural como nos balés Bayadére e Giselle ou ainda na Bela Adormecida de Tchaikovsky. Obra da plena maturidade de Chopin, a Barcarola op. 60 agrega os princípios de repetição com variação contínua e, ao contrários das Baladas e Scherzos, não tem sido alvo de numerosas análises. Nos seus 116 compassos em quaternário composto (12/8), distingue-se por um tratamento contrapontístico sofisticado e por um controle deliberado no adiamento das resoluções de dissonâncias. $O$ arcabouço harmônico que estabelece fá sustenido como tonalidade principal nas seções exteriores (c. 4-39 e c. 86-116) em oposição a lá da seção intermediária (c. 39-83) é sedutoramente poderoso. Em acréscimo, tanto a Coda que Rink descreve como apoteótica (Rink, 1988) quanto às transições na seção intermediária, em especial o dolce sfogato (c. 78-83), tecem as tramas pianísticas mais atrativas da literatura do instrumento. Não é uma obra de virtuosismo no sentido comumente empregado do termo, mas exige do pianista um nível artístico sutil.

Ainda que Chopin se utilize de um delineamento ternário no longo prazo, o desenrolar de eventos não se presta ao encaixe em moldes pré-fixados e, considerando que a música existe enquanto manifestação sonora no momento da sua execução, elegi uma análise nos moldes schenkerianos. Considero que esta abordagem encoraja o entendimento do controle da apresentação, manutenção e

\footnotetext{
2 Em 1786 durante sua célebre viagem à Itália, Goethe descreve como os gondoleiros venezianos cantavam versos de Ariosto e Tasso adaptados à melodia, um registro de barcarola como gênero vocal (Edgecombe, 2001, p. 254).
} 
eventual resolução de dissonâncias em contraste com a tonalidade estável do pano de fundo.

\section{Chopin's Barcarolle op. 60}

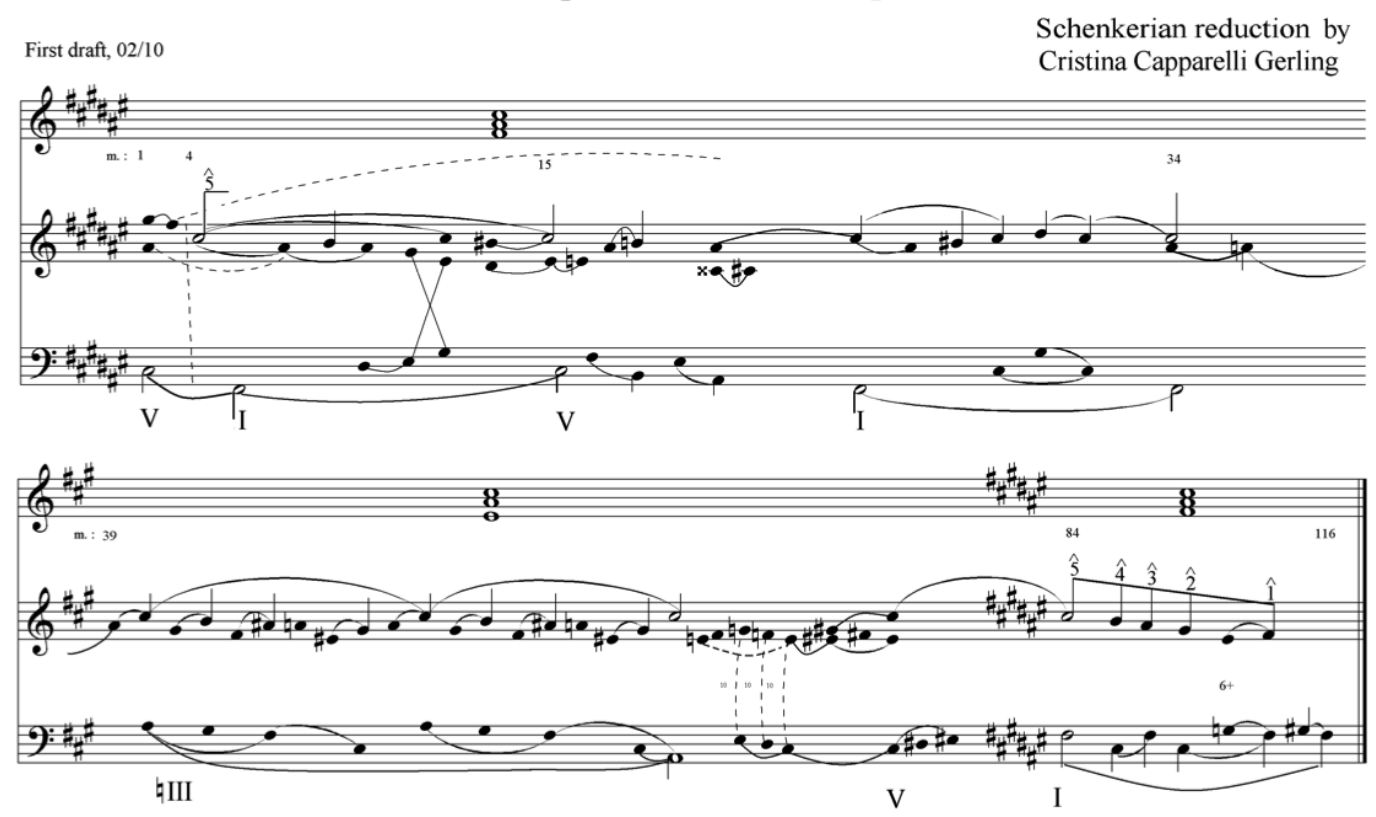

Figura 4. Do nível médio à estrutura fundamental da Barcarola.

Como explicitado acima (fig. 4), trata-se de uma síntese da Barcarola, desta vez em forma de texto musical, mas o esquema ternário fica representado pelas três tríades na linha superior do gráfico, Fá\# Maior, c. 4; Lá Maior, c. 39; Fa\# Maior, c. 84. Além disto, fica evidenciada a centralidade do quinto grau, Do\#, estabelecido no c. 6 como sustentação melódica até o início da descida final (c. 101). As transições com o mais alto teor de invenção nas figurações instrumentais se constituem em momentos verdadeiramente especiais. Assim como na música de Bach, cada retorno em Chopin assinala um adensamento das tramas e um incremento significativo na complexidade do discurso, o que demonstra seu virtuosismo composicional.

Tendo realizado esta etapa, consultei outras análises, a de Rink meticulosa e detalhada (Rink, 1988) e uma crítica da mesma por Schmalfeldt (1990). Na comparação entre os dois analistas, Schmalfeldt chama a atenção em especial para a importância dos eventos compreendidos entre os c. 39 e 51, ou seja, esta analista valoriza e explicita o cromatismo que resulta em acirramento do conteúdo dissonante na passagem. Pude então constatar que minhas intuições estavam basicamente corretas, mas pude também verificar que toda análise é um ato 
interpretativo. A análise nos moldes schenkerianos confirma o esquema ternário e evidencia a organização do discurso musical através de início, meio e fim.

Uma análise para performance da Barcarola pode, com vantagem, agregar os princípios de periodicidade que contém descontinuidade e interrupção, todos tão caros ao compositor; os pontos culminantes que fazem desta obra uma verdadeira festa pianística e por último, mas não menos importante, os modos de enunciação da canção, da dança e da narrativa. Estas categorias frequentemente se justapõem para aumentar a gama de escolhas interpretativas (Agawu, 2009). Levei estas categorias em consideração ao planejar a transformação do texto em som musical.

\section{Registro das primeiras seções de estudo}

Iniciei a leitura da obra no dia 17 de março de 2008 e registrei em vídeo as seções iniciais do estudo transcritas e transformadas em gráficos. Como um pianista iniciante mostram as tentativas e erros, frequente paradas e retomadas.

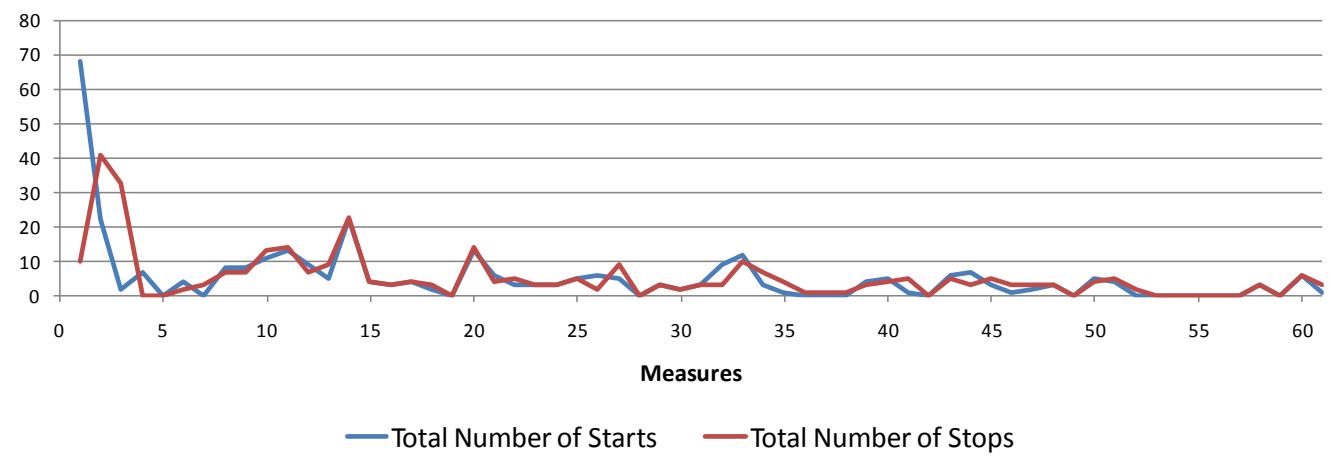

Figura 5. Gráfico com o número de paradas e retomadas em todas as seções.

Como explicitado na figura acima (Fig. 5), o início da obra absorveu minha atenção. Posteriormente este quadro se modifica e o final da obra passou a ser estudado com mais detalhe. 


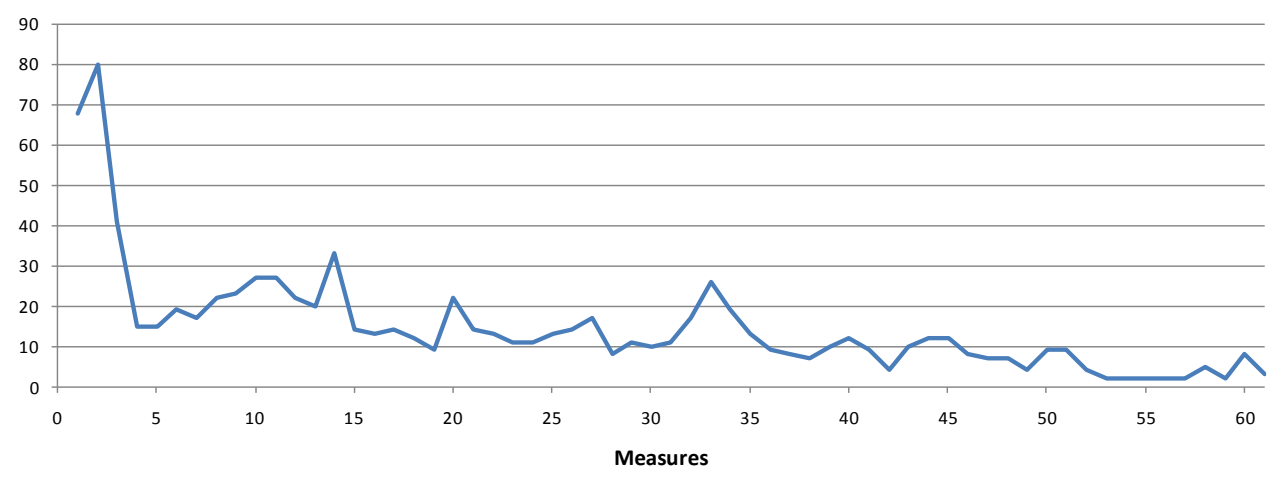

Figura 6. Gráfico com o número de repetições em todas as seções.

No conjunto (veja Figura 6), os gráficos me mostraram que no início meu estudo se assemelha ao dos iniciantes, ou seja, é laborioso e repetitivo. Assim como os iniciantes, me detenho exaustivamente nos primeiros compassos. No entanto, ao final das duas semanas, podia tocar a obra do início ao fim com tropeços mas, havia absorvido a ideia geral. Neste momento, dei início à análise procurando entender a complexidade das tramas contrapontísticas e do resultado harmônico. Publicações recentes confirmam a existência de duas variáveis importantes em relação à prática bem como seu papel determinante na obtenção das metas propostas: a qualidade e a quantidade do estudo, sobretudo na interação com os conhecimentos adquiridos e as competências previamente desenvolvidas. Sloboda (1996, p. 308) declara taxativamente que "a quantidade gasta de maneira informada e relevante no estudo é a variável mais decisiva na aquisição de habilidades musicais e no desempenho de alto nível". Graças à parceria estabelecida com o Performance Music Lab (http://musicpsyc.uconn.edu/) e, sobretudo, graças ao interesse dos pesquisadores em entender como um músico aprende, transpus o estágio inicial de repetição e busquei estratégias mais efetivas como descrito a seguir.

\section{Prática deliberada e memorização}

O estudo (prática) é um fator central e comum a todos os aspectos do desenvolvimento musical (Jørgensen e Hallam, 2009, p. 265). As atividades humanas dependem de etapas e graus de aprendizado, de metas a serem alcançadas, da organização no dispêndio de tempo e do grau de satisfação com a realização. Nesse sentido, meu entendimento de prática não se relaciona somente com o estudo mecânico do instrumento, mas com o desenvolvimento de um conjunto de competências necessárias para o desempenho profissional 
tais como a aquisição de ferramentas interpretativas segundo códigos estilísticos sofisticados, a capacidade de executar de memória, a habilidade de manusear os parâmetros musicais na projeção intencional de elementos estruturais e expressivos, bem como o desenvolvimento da acuidade na audição. Refletindo sobre as etapas percorridas, ressalto a busca do mais alto nível de controle justamente para que adaptações e modificações possam ocorrer de momento a momento na execução de memória. No caso do resgate de dados musicais, não há memória suficiente para resgatar nota a nota, evento a evento, sinal a sinal. Faz-se necessário agrupar eventos menores ligando-os a eventos de duração mais longa ou significado mais abrangente. Desta forma, a análise schenkeriana ${ }^{3}$ potencializa a organização do discurso musical no seu trajeto linear de longo prazo enquanto a análise para performance contribui para resgatar sentimentos, afetos e deliberações intencionais de dinâmica e articulação no médio e curto prazo. Estas estratégias se combinam e se recombinam durante o estudo planejado para que as deliberações fiquem disponibilizadas.

Este tipo de estudo difere das seções iniciais nas quais espontaneamente repeti ao sabor das dificuldades de resolução do texto musical. Se o estudo continuasse neste modo de repetição, eventualmente eu desenvolveria uma série de associações em cadeia. Neste tipo de memorização, cada passagem executada ativa o seguimento do que virá a seguir. A memorização deliberada, por sua vez, transforma a cadeia motora e a auditiva de maneira a ativar as memórias de conteúdo endereçável.

Na medida em que a memorização foi se solidificando pude formular perguntas específicas tais como: Quais são as diferenças e semelhanças entre os compassos 32 e 92 da Barcarola de Chopin? (Chaffin et al, 2009). Buscando desenvolver uma memória de conteúdo endereçável, estudei seguindo o protocolo de Guias de Execução proposto por Chaffin (Chaffin, Imreh, Crawford, 2002). A partir do estudo realizado em junho de 2008, atentei para características e peculiaridades do texto musical para estabelecer categorias designadas por Guias Básicos, Estruturais, Interpretativos e Expressivos. Os guias são pessoais e intransferíveis, cabendo ao instrumentista deliberar quanto à sua aplicação segundo suas necessidades e objetivos. Os Guias Estruturais referem-

\footnotetext{
${ }^{3}$ Heinrich Schenker, analista e musicólogo austríaco (1868-1935) propôs uma teoria unificada da tonalidade, e suas análises são de fato sínteses do desenrolar do discurso musical.
} 
se ao entendimento da partitura organizada em seções, subseções, períodos, frases, terminações e cadências, bem como mudanças no desenho. São os aspectos formais que geram regularidades, interrupções ou descontinuidades.

De antemão, procurei entender o texto da Barcarola levando em consideração o delineamento das seções maiores e o conteúdo frasal. Nesta categoria incluemse os pontos de troca, ou seja, passagens muito semelhantes que seguem caminhos diferenciados. Performances ao vivo se constituem em momentos de tensão justamente nos pontos onde pode haver confusão na continuidade; o estudo dos pontos de troca, tão frequentes quanto sutis na Barcarola, foi um dos aspectos mais valorizados durante o aprendizado. Nos dois exemplos a seguir, demonstro pontos de troca com elevado valor estrutural e expressivo nos c. 32 e 92 respectivamente (Fig. 7 e 8 ).

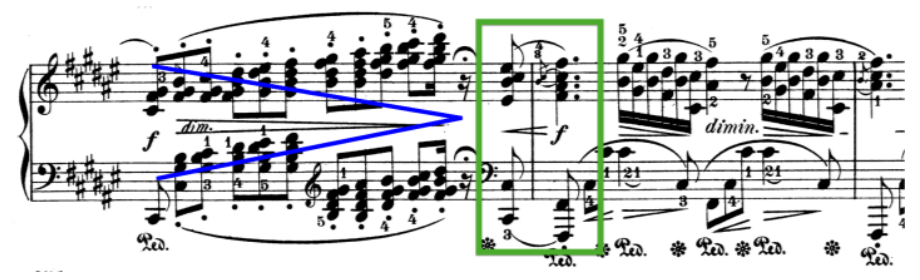

Figura 7. Ponto de troca nos c. 32-33.

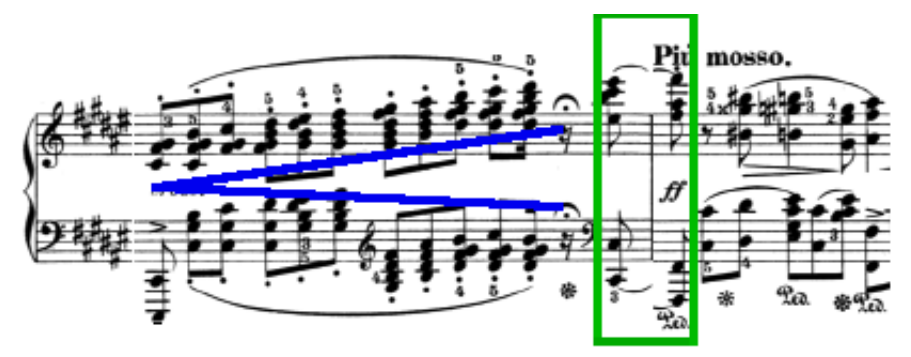

Figura 8. Ponto de troca nos c. 92-93.

Desde as primeiras leituras procurei salientar os pontos de troca, uma característica proeminente da música tonal, sejam segmentos musicais com conteúdo semelhante ou idêntico que conduzem para diferentes seções como no exemplo acima, ou modificações sutis no acompanhamento. 
As diferentes modalidades de análises foram suplementadas pelas audições de gravações, um hábito que cultivo e que considero tão importante quanto a revisão bibliográfica na escrita de um texto. Aprendo e memorizo pelo ouvido e esta informação sobre minhas preferências de aprendizagem resulta em eficiência e ganho de tempo. Além disto, o gosto musical se desenvolve através da familiaridade com um certo repertório sendo portanto uma construção cultural (Becker, 2001, p. 129). A execução musical em níveis avançados de excelência depende de habilidades técnicas refinadas porque diferenças muito sutis na manipulação do tempo (microvariações temporais) (Repp, 1988, 1997) determinam o conjunto de qualidades sonoras e artísticas. Refletem também a acuidade e a sofisticação do aparato auditivo do músico. As diferenças, que conferem o perfil individual de cada intérprete, podem ser analisadas através de registros fonográficos (Gerling, 2008; Matschulat, 2011). De fato, após mais de um século, o acervo de obras gravadas abriu um novo campo de pesquisa musicológica (Clarke, 2004) através de estudos comparativos determinantes para o entendimento do pensamento estético musical através das décadas (Bowen, 1993). Mesmo não tendo como saber como Chopin tocava, ${ }^{4}$ posso analisar a performance de renomados pianistas registradas desde o início do século XX. O número de registros fonográficos da Barcarola, de forma inversamente proporcional ao das análises, é contado por centenas. Tem sido uma das obras preferidas dos concorrentes no Concurso Chopin de Varsóvia desde 1927. Como parte do estudo deliberado desta obra ouvi e comparei mais de 40 gravações. A seguir apresento uma comparação dos tempos empregados por nove pianistas de diferentes gerações, incluindo os mais jovens ganhadores recentes do Concurso Chopin de Varsóvia. As comparações estão baseadas nas realizações musicais quanto às mudanças de andamento solicitadas por Chopin (Fig. 9 e 10):

\begin{tabular}{|l|l|l|l|l|l|l|}
\hline C. 1 & c. $4-6$ & c. $34-40$ & c. 62 & c. $71-74$ & c. 93 & c. 111 \\
\hline
\end{tabular}

4 Há uma descrição de Chopin tocando a Barcarola já combalido pela doença. Nessa ocasião Chopin inverteu todos os sinais de dinâmica tendo a obra a partir do c. 84 que contém indicações explícitas de $f$ e $f f$, com uma dinâmica de extraordinária delicadeza e nuances de $p$ e $p p$. 


\begin{tabular}{|l|l|l|l|l|l|l|}
\hline Introdução & Allegreto & $\begin{array}{l}\text { poco piu } \\
\text { mosso }\end{array}$ & $\begin{array}{l}\text { poco piu } \\
\text { mosso }\end{array}$ & $\begin{array}{l}\text { meno } \\
\text { mosso }\end{array}$ & $\begin{array}{l}\text { piu } \\
\text { mosso }\end{array}$ & calando \\
\hline
\end{tabular}

Figura 9. Principais indicações de mudanças de andamento na partitura da Barcarola.

\begin{tabular}{|l|r|rr|l|}
\hline Pianistas & $\mathrm{m} .1-3,4-7$ & $\mathrm{~m} .28$ & 40 & $\mathrm{~m} .88-96$ \\
\hline Antonieta Rudge & $60-70$ & $90-40$ & 62 & $100+-88+$ \\
\hline Leff Puishnoff & $44-48$ & $86-46$ & 80 & $72-112$ \\
\hline Heinrich Neuhaus & $64-70$ & $72-55$ & 70 & $66-100+$ \\
\hline Alfred Cortot & $67-70$ & $66-40$ & 60 & $66-82$ \\
\hline Arthur Rubinstein & $65-70$ & $64-40$ & 60 & $70-92$ \\
Vladimir Horowitz & $55-60$ & $62-45$ & 102 & $66-84$ \\
\hline Rafal Blechazc & $58-64$ & $62-38$ & 62 & $62-114$ \\
\hline Lukas Geniusas & $58-61$ & $60-48$ & 72 & $60-100+$ \\
Daniil Trifonov & $54-66$ & $81-59$ & 56 & $80-92$ \\
\hline
\end{tabular}

Figura 10. Pianistas selecionados e tempos aproximados (bpm).

As comparações dos tempos escolhidos e adotados pelos pianistas na tabela anterior (Figura 10) podem ser melhor explicitados nos gráficos a seguir.

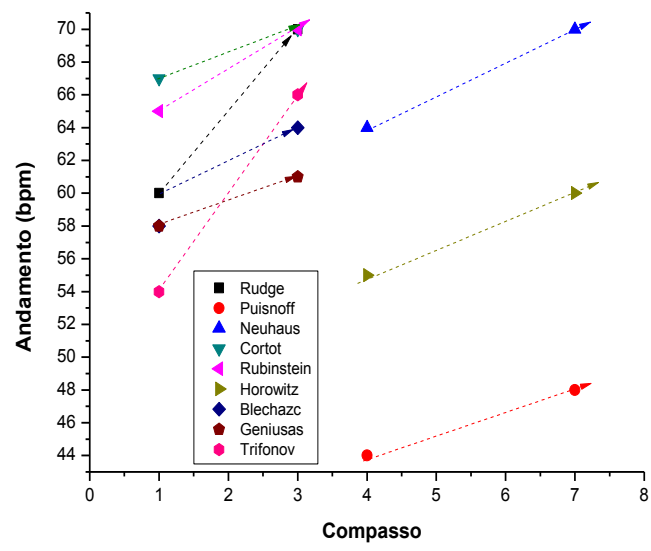

Figura 11. Variação de tempo nos c. 1-7.

Como exemplificado na Figura 11, os pianistas, sem exceção efetuam um aumento de velocidade nos compassos de abertura da Barcarola. Puishnoff, por exemplo, inicia com o tempo mais vagaroso nos dois segmentos (c.1-3 e 4-7), mas o impulso para frente é uma escolha de todos os selecionados. Trata-se de um início dissonante e intensamente dramático. O impacto da primeira sonoridade precisa de tempo para ecoar, mas eventualmente o discurso musical precisa ser retomado; o "tempo de barcarola" requer uma propulsão ondulante. 


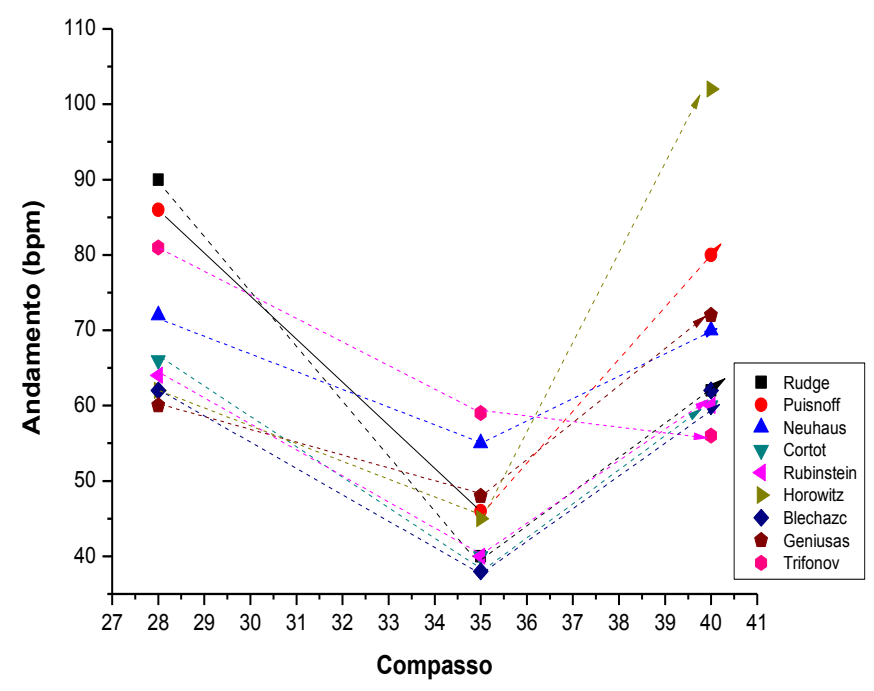

Figura 12. Variação de tempo nos c. 28-40.

A solicitação de Chopin quanto rallentando, que antecede o "poco piu mosso" do c. 35 é atendida por todos os pianistas, com perda gradual porém nítida da velocidade (veja Figura 12Erro! Fonte de referência não encontrada.). Uma vez ultrapassado o c. 35, Horowitz realmente se entusiasma com a possibilidade de alcançar um andamento bem rápido nesta passagem e no espaço de três compassos atinge uma dobra da velocidade. Os demais instrumentistas executam o accelerando com variados graus de parcimônia.

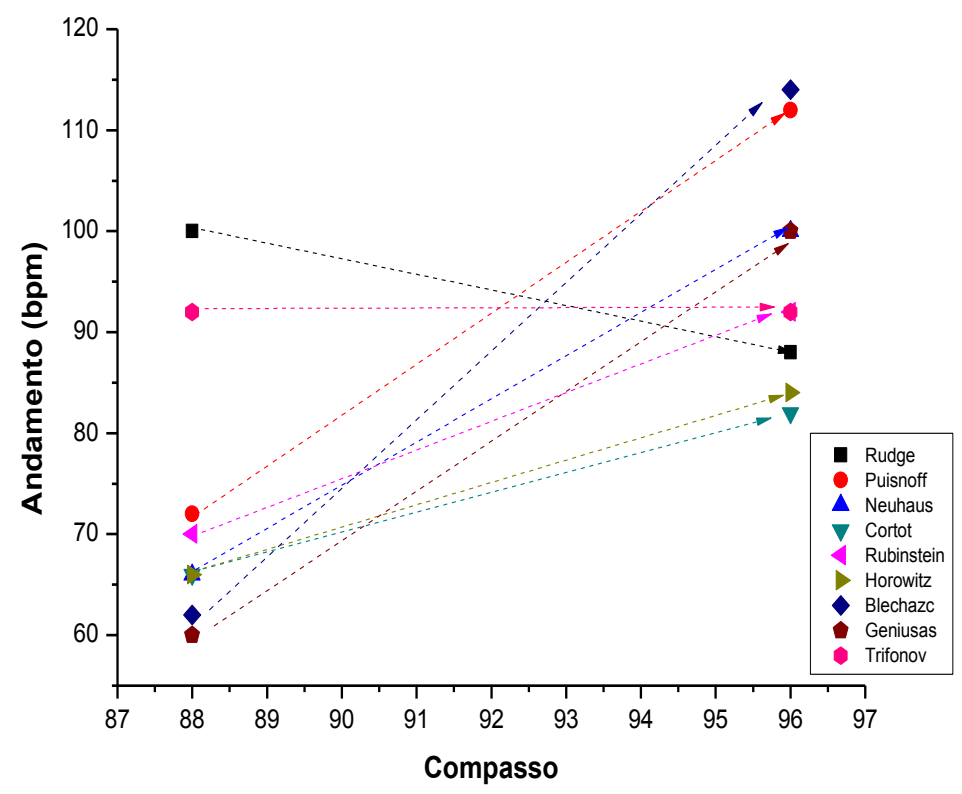

Figura 13. Variação de tempo nos c. 88-96. 
Um aspecto epistemológico envolvido na execução musical refere-se ao fato de que a execução instrumental não lida com descobertas, mas com invenções e criações. Desta forma, nossa Antonieta Rudge (1885-1974) inova com uma perda de velocidade no momento em que os demais pianistas optaram por um acréscimo neste parâmetro (veja Figura 13). Quanto ao tempo total de execução, Rudge despende 8,18 minutos contra uma média de mais de 9 minutos para os demais. A escuta de gravações amplia exponencialmente a gama de possibilidades interpretativas não como cópia, mas como modelagem, uma estratégia que suscita reflexão para tomada de decisões interpretativas entre várias alternativas (Lisoba et al, 2005; Freitas, 2013).

Após as primeiras quarenta horas de estudo apresentei a Barcarola pela primeira vez em fevereiro de 2009 para um público restrito, ainda que constituído por músicos experientes. Cada apresentação subsequente trouxe novas reflexões para novas decisões interpretativas, a busca pelo crescimento artístico. A memória ou a fluência em si não se constituíram em entrave visto que procurei e continuo procurando capturar a complexidade do todo e a nitidez de cada detalhe. Continuo sim buscando o inefável, o mágico e o intangível, o que se aprende no compartilhamento com a audiência. 


\section{Referências bibliográficas}

AGAWU, Kofi. Music as Discourse, Semiotic Adventures in Romantic Music. Oxford: Oxford University Press, 2009.

BECKER, Judith. Anthropological Perspectives on Music and Emotion. In: JUSLIN, Patrick N. and SLOBODA, John A. Music and Emotion. Theory and Research. Oxford: Oxford University Press, 2001.

BOWEN, Jose A. The History of Remembered Innovation: Tradition and its Role in the Relationship between Musical Works and their Performances. The Journal of Music Theory, Xi, 139-168, 1993.

CHAFFIN, Roger; IMREH, Gabriela; CRAWFORD, Mary. Practicing perfection: Memory and piano performance. Mahwah: Erlbaum, 2002.

CHAFFIN, Roger; LEMIEUX, Anthony F; CHEN, C. Spontaneity and creativity in highly practised performance. In: DELIĖGE, Irène; WIGGINS, Geraint A. (Eds.). Musical Creativity. Howe: Psychology Press, 2006, p. 200-218.

CHAFFIN, Roger; LEMIEUX, Anthony F.; CHEN, Colleen. It's Different Each Time I Play: Spontaneity in Highly Prepared Musical Performance. Music Perception, 24, 455-472, 2007.

CLARKE, Eric F. Empirical Methods in the Study of Performance. In: CLARKE, Eric F. and COOK, Nicholas. (Eds.). Empirical Musicology: Aims, Methods, Prospects. Oxford: Oxford University Press, 2004. p. 77-102.

CLARKE, Eric F. Creativity in Performance. Musicae Scientiae. 9 (1), p. 157-182, 2005.

CLARKE, Eric F. Generative principles in music performance. In: SLOBODA, John A. (Ed.). Generative Processes in Music: The Pscyhology of Performance, Improvisation, and composition. Oxford: Oxford University Press, 1988, p. 1-26.

CONE, Edward T. Musical Form and Musical Performance. New York, Norton, 1968.

DAVIES, Stephen. Philosophical perspectives on music's expressiveness. In:

SLOBODA, John; JUSLIN, Patrik. (Eds.) Music and emotion. Theory and Research. Oxford: Oxford University Press, 2004. p. 23-44.

DOMENICI, Catarina. O intérprete (re)situado: uma reflexão sobre construção de sentido e tecncia na criação de Intervenções para piano expandido, interfaces e imagens: Centenário John Cage. Revista Música Hodie, Goiânia, v.12 - n. 2, 2012, p. 171-187.

EDGECOMBE, Rodney Stenning. On the Limits of Genre: Some NineteenthCentury Barcarolas. 19th-Century Music, v. XXIV, n. 3, p. 252-267, 2001.

EIGERLDINGER, Jean-Jacques. Chopin pianist and teacher as seen by his pupils. Cambridge: Cambridge University Press, 1986.

ELLIOT, D.J. Music Matters. New York: Oxford University Press, 1995.

ERICSSON, K.A. Deliberate practice and the acquisition of expert performance: An overview. In: JØRGENSEN, Harald; LEHMANN, Andreas C. (Eds). Does practice make perfect? Oslo: Norges musikkhøgskole, 1997. p. 9-52.

FREITAS, Stefanie. Modelagem como estratégia de aprendizado: Três Estudos de Caso com Bacharelandos em Piano, Tese de Doutorado, UFRGS, 2013. 
GABRIELSSON, Alf. The perfomance of music. In: DEUTSCH, Diana. (Ed.) The Psychology of Music. 2 ed. San Diego: Academic Press, pp. 501-602, 1999.

GABRIELSSON, Alf. Music performance research at the Millenium. Psychology of Music, v. 31, pp. 221-272, 2003.

GERLING, Cristina C.; SANTOS, Regina A. T. A comunicação da expressão na execução musical ao piano. In: 3rd Symposium on Cognition and Musical ArtsInternational, 2007, Salvador. Proceedings. Salvador: UFBA, 2007. v. 1. p. 147154.

GERLING, Cristina C.; SANTOS, Regina A. T. Intended versus perceived emotion. In: AEC. (Org.). International Symposium on Performance Science: theories, methods and applications in Music. 1 ed. Oporto: AEC, 2007, v. 1, p. 233-238.

GERLING, Cristina C; SOUZA. Jusamara. A performance como objeto de investigação. Anais do I SINCAM, Belo Horizonte, 2000, v. I. p. 122-150.

GERLING, Cristina M. P. C; GUSMÃO, Pablo da Silva. O Tempo e a Dinâmica na Construção de uma Interpretação Musical. In: Sonia Ray. (Org.). PERFORMANCE MUSICAL E SUAS INTERFACES. S.n ed. Goiânia, Goiás: Editora Vieira, 2005, v. 1, p. 65-94.

GERLING, Fredi V. O tempo rubato na Valsa de Esquina N. ${ }^{2} 2$ de Francisco Mignone, Claves, João Pessoa, n. 5, 2008, p. 7-19.

GODOY, Rolf I.; JENSENIUS Alexander R. Body Movement in Music Information Retrieval. In: Keiji, Hirata; George, Tzanetakis \& Kazuyoshi, Yoshii (ed.), ISMIR2009 - Proceedings of the 10th International Society for Music Information Retrieval Conference. International Society for Music Information Retrieval, 45 50, 2000.

HALLAM, Susan; CROSS Ian; THAUT, Michael (Orgs). The Oxford Handbook of Music Psychology. Pxfprd: Oxford University Press, 2009.

JENSENIUS, Alexander R.; WANDERLEY, Marcelo M.; GODOY, Rolf I.; LEMAN, Mark. Musical Gestures: concepts and methods in research, In: INGE GOD $\varnothing Y$, Rolf \& LEMAN, Marc.(Ed.). Musical Gestures: Sound, Movement, and Meaning. Routledge, 2010, p. 12-35.

HURON, David. Sweet Anticipation, Music and the psychology of Expectation. MIT Press, 2007.

JØRGENSEN, Harald. Student learning in higher instrumental education: who is responsible? British Journal of Music Education, v. 17, p. 67-77, 2000.

JØRGENSEN, Harald; LEHMANN, Andreas C. Does practice make perfect? Oslo: Norges musikkhøgskole, 1997.

JUSLIN, P. N. Five facets of musical expression: a psychologist's perspective on music performance. Psychology of Music, v. 31, p. 273-302, 2003.

JUSLIN, Patrick N; FRIBERG, Anders; SCHOONDERWALDT, Erwin; KARLSSON, Jessica. Feedback learning of musical expressivity. In: WIILLIAMON, Aaron. (Ed.), Musical Excellence. Strategies and techniques to enhance performance. New York: Oxford University Press, p. 247-270, 2004.

LEHMANN, Andreas C. Acquired mental representations in music performance: Anecdotal and preliminary empirical evidence. In: JØRGENSEN, Harald; LEHMANN, Andreas C. (Eds). Does practice make perfect? Oslo: Norges musikkhøgskole, pp. 141-163, 1997. 
LISBOA, Tania; WILLIAMON, Aaron; ZICARO, Massimo; EINHOLZER, Hubert. (2005), Mastery Through Imitation: A Preliminary Study. Musicae Scientiae, 9, (1) 75-110.

MATSCHULAT, Josias. Gestos Musicais no Ponteio n 49 de Camargo Guarnieri: Uma Análise e Comparação de Gravações. Dissertação (Mestrado em Pós Graduação em Música Mestrado e Doutorado UFRGS), 2011.

MCPHERSON, Gary E. Motivational and self-regulated learning components of musical practice. Bulletin of the Council for Research in Music Education, v. 141, p. 98-102,1999.

PARNCUTT, Richard; McPHERSON, Gary E (Eds.). The science and psychology of music performance. Oxford: University Press, 2002.

PERSSON, Roland S. The subjective world of the performer. In: Music and emotion. Theory and Research. JUSLIN, Patrik N.; SLOBODA, John A. (Eds.) Oxford: Oxford University Press, p. 275-289, 2004.

RINK, John. The Barcarolle: Auskomponierung and Apotheosis, In: SAMSON, Jim. (Ed.) Chopin Studies. Cambridge: Cambridge University Press, 1988. p. 198-219. RINK, John. (Ed.) The Practice of Performance: Studies in Musical Interpretation. Cambridge: Cambridge University Press, 1995.

RINK. John.; Musical Performance: A guide to understanding. Cambridge:

Cambridge University Press, 2002.

RINK, John. (2003), Chopin Copying Chopin, In: Szklener, Artur (Ed.). Chopin's Work: His Inspirations and Creative Process in the Light of the Sources. Warsaw: Narodowy Instytut Fryderyka Chopina, p. 67-81.

REID, Stefan. Preparing for Performance. In: RINK, John. Musical Performance: a guide to understanding. Cambridge: Cambridge University Press, 2002, p. 102112.

REPP, Bruno H. Expressive Timing in a Debussy Prelude: A comparison of student and expert pianists. Musicae Scientiae, I, 257-268, 1997.

REPP, Bruno H. Microcosm of musical expression: II. Quantitative analysis of pianists 'dynamics in the initial measures of Chopin's Etude in E Major. Journal of the Accoustical Society of America, I105, 1972-1988.

SANTIAGO, Diana F. A integração da prática deliberada e da prática informal no aprendizado instrumental. PerMusi, XIII, 2006, 52-62.

SANTOS, Regina Antunes dos. A mobilização de conhecimentos musicais na preparação do repertório pianístico: três estudos de caso. Porto Alegre: UFRGS, 2007 (Tese, doutorado em música).

SCHMALFELDT, Janet. On the Relation of Analysis to Performance: Beethoven's Bagatelles op. 126, Nos. 2 and 5. Journal of Music Theory 29 (1), p. 1-31, 1985. SCHMALFELDT, Janet. Review [Untitled]. Music Theory Spectrum, Xii (2), p. 262275, 1990.

SLOBODA, John A. Exploring the musical mind. Oxford: Oxford Universit Press, 2005.

SLOBODA, John A; DAVIDSON, Jane W.; HOWE, Michael J.A.; MOORE, Derek C. The role of practice in the development of performing musicians. British Journal of Psychology, v. 87, p.287-309, 1996. 
WEISBERG, Robert W. Creativity and knowledge: A challenge to Theories. In: STERNBERG, Robert J. (Ed.) Handbook of creativity. New York: Cambridge University Press, 1999.

WILLIAMON, Aaron. Musical Excellence. Strategies and techniques to enhance performance. Oxford: University Press, 2004.

WÖLLNER, Clemens; WILLIAMON, Aaron. An Exploratory Study of The Role of Performance Feedback and Musical Imagery in Piano Playing. Research Studies in Music Education. 29 (39), 2007. 